\title{
Effect of different curing conditions on compressive strength and durability of kenaf fibre reinforced blended cementitious composites
}

\author{
$R$. Ahmad, $R$. Hamid*, and S. A.Osman
}

Smart and Sustainable Township Research Centre, Faculty of Engineering and Built Environment, Universiti Kebangsaan Malaysia, 43600 UKM Bangi, Selangor, Malaysia

\begin{abstract}
This paper investigates the effect of normal curing (NC), air curing (AC), and burlap curing (BC) under different curing periods on the mechanical strength and durability of kenaf fibre reinforced blended cementitious composites (KFRBCC) with thermally activated alum sludge ash (AASA). The aim is to determine the most efficient condition and period for curing KFRBCC and to assess the effect of accelerated ageing on strength and durability of KFRBCC after wet/dry cycles. Meanwhile, the microstructure of these mixes is observed via scanning electron microscopy (SEM). The KFRBCC is designed to achieve strength beyond $50 \mathrm{MPa}$ after 28 days (d) of curing by adding $2 \%$ treated kenaf fibre (KF) and by replacing Ordinary Portland Cement (OPC) with AASA. The findings suggest that compressive strength and durability of KFRBCC with $40 \%$ AASA cured under BC after age of $28 \mathrm{~d}$ are enhanced. The addition of treated KF with AASA have helped in limiting the reduction in the compressive strength and durability of the KFRBCC, particularly under prolonged curing period.
\end{abstract}

\section{Introduction}

The most influential factors on mechanical and durability of cementitious composites is a satisfactory curing condition for adequate moisture content and temperature to assist the hydration of OPC and to attained higher strength [1]. The importance of curing is critical in the mixtures contains pozzolanic materials, or are otherwise intended to meet specific performance requirements [2]. Curing for concrete containing pozzolanic material takes at least 4 weeks due to pozzolanic reaction occurs at the mature age of more than $28 \mathrm{~d}$ which enhance the durability [3]. Compressive strength should also be characterize along with durability to identify the satisfactory performance of composite and to withstand the damaging effects of environmental factors under severe service conditions. Several researchers working on improvement of concrete strength and durability by incorporation of pozzolans in mixes [4-5]. The use of pozzolans in concrete results in reduction of early

*Corresponding author: roszilah@ukm.edu.my 
strength and increase in late strength which require high replacement contents of pozzolans [6-7] and AASA also shows this behaviour [8].

The alum sludge (AS) are classified as a Class $\mathrm{N}$ pozzolans while AASA is similar to thermally activated kaolin after calcination at $800{ }^{\circ} \mathrm{C}$ [9] and Tantawy [10] approved that calcination at $800{ }^{\circ} \mathrm{C}$ is adequate to improve the pozzolanic properties of AS. The strength of composites improves with the presence of AASA as partial replacement of OPC, but the optimum replacement to accelerated long term strength enhancement and durability has been reported between 10 to 30\% [11-12]. The replacement of AASA are in percentage by wt. of the total binder material. This study will investigate the replacement level of AASA with treated KF, strength and durability improvement of KFRBCC under different curing conditions. Benli et al. [13] investigated the effects on the mechanical properties of FA selfcompacting mortars in $\mathrm{WC}$ and $\mathrm{AC}$ at different curing periods. The findings indicate that mortar cured in WC gave highest compressive strength for $180 \mathrm{~d}$. According to Amjadi et al. [14], the mechanical strength of mortar improved at extended curing period and the pozzolans added into the mixes has help to accelerate the pozzolanic reaction at later ages.

The objective of the research was to obtain the required strength and durability during the life cycle of KFRBCC for future applications in construction in which offering a good alternative for recycling AS. Determination of the appropriate method of curing is one of the base for producing a composite with the strength and durability in the long term.

\section{Experimental procedures}

\subsection{Materials}

Type I OPC complying with ASTM C150 and AASA was used to produce KFRBCC with randomly dispersed short KF. The chemical composition are shown in Table. 1. AS was oven dried at $105 \pm 5^{\circ} \mathrm{C}$ for 24 hours (h) and later the dried AS was calcined in furnace oven at heating rate of $5{ }^{\circ} \mathrm{C} / \mathrm{min}$ at $800{ }^{\circ} \mathrm{C}$ for $2 \mathrm{~h}$ to achieve the thermal steady state. Then, the AASA was allowed to cool gradually to the room temperature. AASA was ground in steel ball mill until the fineness reach the specification recommended by ASTM C618-17 and sieved using $45 \mu \mathrm{m}$ sieve to increase the pozzolanic reaction.

Table 1. Chemical composition of ordinary Type 1 Portland cement and AASA.

\begin{tabular}{|c|c|c|c|c|c|c|c|c|c|c|c|c|c|c|}
\hline \multirow{2}{*}{$\begin{array}{c}\text { Chemi } \\
\text { cal } \\
\text { compo } \\
\text { sition } \\
(\%)\end{array}$} & $\begin{array}{c}\mathrm{Si} \\
\mathrm{O} 2\end{array}$ & $\begin{array}{c}\mathrm{A} 12 \\
\mathrm{O} 3\end{array}$ & $\begin{array}{l}\mathrm{Fe} \\
2 \mathrm{O} \\
3\end{array}$ & $\begin{array}{c}\mathrm{Ca} \\
\mathrm{O}\end{array}$ & $\begin{array}{c}\mathrm{M} \\
\mathrm{g} \\
\mathrm{O}\end{array}$ & $\begin{array}{l}\mathrm{M} \\
\mathrm{gO}\end{array}$ & $\begin{array}{l}\mathrm{Na} \\
2 \mathrm{O}\end{array}$ & $\begin{array}{l}\mathrm{K} \\
2 \\
\mathrm{O}\end{array}$ & $\begin{array}{l}\text { Los } \\
\text { s of } \\
\text { Igni }\end{array}$ & $\begin{array}{l}\text { Spec } \\
\text { ific } \\
\text { gravi }\end{array}$ & $\begin{array}{l}\text { Fine } \\
\text { ness }\end{array}$ & $\begin{array}{c}\text { Median } \\
\text { Particle } \\
\text { Size }\end{array}$ & \multicolumn{2}{|c|}{$\begin{array}{l}\text { Pozzolanic } \\
\text { Activity } \\
\text { Index }(7 \mathrm{~d})\end{array}$} \\
\hline & & & & & & & & & & & $\begin{array}{c}\mathrm{m} 2 / \mathrm{k} \\
\mathrm{g}\end{array}$ & $\mu \mathrm{m}$ & $7 d$ & $28 \mathrm{~d}$ \\
\hline OPC & $\begin{array}{c}20 . \\
18\end{array}$ & $\begin{array}{c}5.2 \\
3\end{array}$ & $\begin{array}{c}3.3 \\
4\end{array}$ & $\begin{array}{c}64 . \\
4\end{array}$ & $\begin{array}{l}1 . \\
8\end{array}$ & $\begin{array}{c}0 . \\
07\end{array}$ & $\begin{array}{c}0.4 \\
4\end{array}$ & $\begin{array}{l}2 . \\
17\end{array}$ & $\begin{array}{c}3.1 \\
5\end{array}$ & 338 & 16.9 & 100 & $\begin{array}{c}10 \\
0\end{array}$ & $\begin{array}{c}20.1 \\
8\end{array}$ \\
\hline AASA & 47 & $\begin{array}{l}41 . \\
94\end{array}$ & $\begin{array}{c}4.8 \\
6\end{array}$ & $\begin{array}{c}0.4 \\
1\end{array}$ & $\begin{array}{l}0 . \\
4\end{array}$ & $\begin{array}{c}0 . \\
09\end{array}$ & $\begin{array}{c}0.9 \\
9\end{array}$ & $\begin{array}{l}2 . \\
64\end{array}$ & $\begin{array}{c}2.5 \\
3\end{array}$ & 11.6 & 10.1 & 84 & 93 & 47 \\
\hline
\end{tabular}

$10 \mathrm{~mm}$ length $\mathrm{KF}$ were treated with $6 \% \mathrm{w} / \mathrm{w} \mathrm{NaHCO}_{3}$ alkali solution and immersed for $72 \mathrm{~h}$. After the treatment, KF were thoroughly washed with running water to remove absorbed alkali from the fibre surface. The washed KF were allowed to dry at room temperature for $24 \mathrm{~h}$ and then oven dried for thermal treatment at $70{ }^{\circ} \mathrm{C} \pm 5^{\circ} \mathrm{C}$ for $24 \mathrm{~h}$ to release lignin and increase the crystallinity index (CrI) of the $\mathrm{KF}$ before added into the mixes. Superplasticizer (SP) was used to control the flow of mortar. $4.5 \%$ of low viscosity 
liquid Darex Super 20 is the maximum dose for mixes but the doses use are vary to comply flow rate.

\subsection{Mix proportion and preparation of specimens}

Eight mixes were cast with $2 \%$ volume fraction of KF by volume of total mix design (constant for all mixes) into standard cube $100 \mathrm{~mm}$ with cement/sand (s/c) ratio of 1:2. Optimum water/cement (w/c) ratio was obtained at 0.4 (constant for all mixes) after three different ratio of $0.3,0.4$, and 0.45 were used for trial mix. The amount of AASA $(20,30$, and $40 \%$ ) are added into mixture for partial replacement of OPC. The mix proportions of the composites are given in Table 2. The composite with $100 \%$ OPC and cured in NC was used as control specimen.

Table 2. Mortar mix proportion.

\begin{tabular}{|c|c|c|c|c|c|c|c|c|c|c|}
\hline Index & $\begin{array}{c}\text { w/b } \\
\text { ratio }\end{array}$ & Cement & Sand & AASA & $\begin{array}{c}\text { Wate } \\
\text { r }\end{array}$ & SP & Fiber & \multicolumn{2}{|c|}{$\begin{array}{c}\text { Curing } \\
\text { Conditions }\end{array}$} \\
\hline & & $(\mathrm{g})$ & $(\mathrm{g})$ & $(\mathrm{g})$ & $(\mathrm{g})$ & $(\%)$ & $(\%)$ & $\mathrm{NC}$ & $\mathrm{AC}$ & $\mathrm{BC}$ \\
\hline OPC1 & 0.30 & 192 & 384 & 0 & 58 & 0 & 0 & $/$ & & \\
\hline OPCR2 & 0.40 & 151 & 378 & 0 & 76 & 3.5 & 2 & $/$ & & \\
\hline AASA20 & 0.40 & 161 & 378 & 28 & 76 & 4.5 & 2 & $/$ & $/$ & $/$ \\
\hline AASA30 & 0.40 & 151 & 378 & 38 & 76 & 4.5 & 2 & $/$ & $/$ & $/$ \\
\hline AASA40 & 0.40 & 132 & 378 & 57 & 76 & 4.5 & 2 & $/$ & $/$ & $/$ \\
\hline
\end{tabular}

\subsection{Curing conditions of test specimens}

The specimens were demoulding after $24 \mathrm{~h}$ and then exposed to the selected curing condition. The average temperature recorded in the laboratory was $27 \pm 2{ }^{\circ} \mathrm{C}$ with relative humidity, $\mathrm{RH} 85 \pm 5 \%$. The cementitious mortar specimens were removed from curing conditions $24 \mathrm{~h}$ before testing and the maximum curing age was $180 \mathrm{~d}$ for all conditions due to slower hydration rate than OPC. For NC, the curing conditions involving specimen immersed in water outside the laboratory and for $\mathrm{AC}$, the specimen were exposed to the ambient air in the laboratory. The specimens were covered with wet burlap outside the laboratory for BC. The burlap was immersed in water every $2 \mathrm{~d}$ to control the moisture content. Three specimens were tested after $28 \mathrm{~d}$ of curing for wet/dry cycle whilst for compressive strength, after $180 \mathrm{~d}$ of curing.

\section{Test procedures}

\subsection{Compressive strength and wet/dry cycles}

The average of three samples were tested for compressive strength test following ASTM C109 and the reported compressive strengths were determined at various ages of 28, 56, 90 and $180 \mathrm{~d}$. For wet/dry cycles, specimens was covered with a piece of plastic and left in laboratory. After 24 hours, the specimen is removed from the mould and soaked in tap water for $15 \mathrm{~h}$ and left to dried for $1 \mathrm{~h}$ in laboratory. Next, the specimen is exposed to a temperature of $70 \pm 5{ }^{\circ} \mathrm{C}$ for $25 \mathrm{~h}$ in the ventilated oven and left to cool down gradually to room temperature in the oven with the door slightly open to prevent excessive cooling. Each wet/dry procedure represent a cycle within 24 hours and performed by 10, 20, 30, and 60 cycles, respectively. 


\section{Result and discussion}

\subsection{Effects of curing conditions on the compressive strength development of mortar}

Compressive strength development results of KFRBCC for different curing conditions are presented in Fig. 1(a-c) and when OPC was replaced by $20 \%$ AASA, the strength of specimens is increased up to $30.6 \%$ compared to control specimen (OPC1 and OPCR1). The incorporation of $40 \%$ AASA by wt. of OPC increased the mechanical strength of cementitious composite about $34.3 \%$ after 28 d due to smaller particle size of AASA and higher surface contact between fibres and mortar. The strength continued to increase by an average rate of $10 \%$ for each specimen up to the age of $180 \mathrm{~d}$ and the rate after $28 \mathrm{~d}$ are more significant for the strength development. This maybe owing to the higher pozzolanic reaction of AASA at later age compared to early age.

The specimens cured by BC provide the highest compressive strength of $20.3 \%$, attributed to the suitable curing conditions compared to $\mathrm{NC}$ and $\mathrm{AC}$. The increase in strength also related to hot weather with high humidity, which increased the rate of cement hydration during the early stage of curing. It could be observed from all of the curing conditions, $\mathrm{BC}$ produced composite specimen that met the targeted compressive strength of $50 \mathrm{MPa}$ and $\mathrm{NC}$ has the lowest compressive strength of $47.32 \mathrm{MPa}$, while $\mathrm{AC}$ recorded the strength of $47.74 \mathrm{MPa}$ at $180 \mathrm{~d}$ respectively. It was observed that the strength increases with increase in AASA content (20 to 40\%) and curing periods for all types of curing conditions and reaches maximum $50.34 \mathrm{MPa}$ for $180 \mathrm{~d}$ in $40 \%$ replacement of AASA with OPC. Obviously, AASA and treated KF can be effectively used to improve the strengths of $\mathrm{KFRBCC}$ with $\mathrm{BC}$ at a later age. In addition, the $28 \mathrm{~d}$ compressive strengths of KFRBCC were found to be higher than mixture containing OPC alone. As for mixture containing AASA, similar results was reported and suggesting that AASA is more effective in increasing the strengths of KFRBCC. This shows that the replacement of OPC with AASA has the effect of filling with fibre dispersed randomly. This proved that curing conditions is one of the most important parameters to improved microstructure by improving the water holding capacity of composites in which curing involves maintaining sufficient moisture content to the last stage of the placement of the composite.

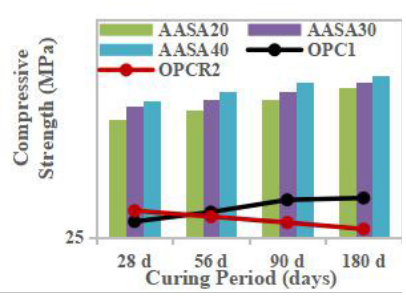

(a)

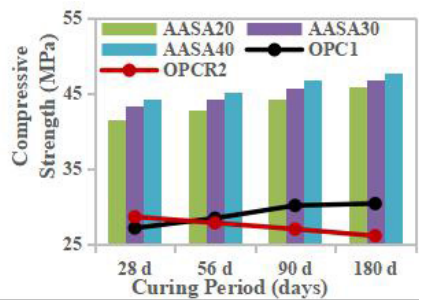

(b)

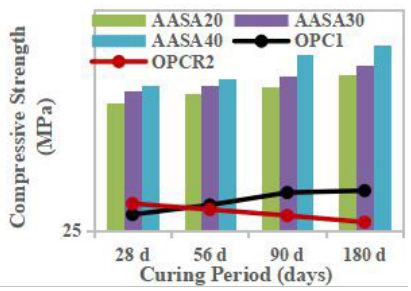

(c)

Fig. 1. Compressive strength for different curing conditions a) NC, b) AC and c) BC.

\subsection{Effect of curing conditions on residual compressive strength of concrete mixes subjected to wet/dry cycling}

The effect of wet/dry cycling on the residual compressive strength for specimens cured for $28 \mathrm{~d}$ in NC, AC, and BC are shown in Fig. 2. After 10 wet/dry cycles $(30 \mathrm{~d})$, all specimens showed reduction in the compressive strength. This result point to the mineralization of KF where fibre became slightly brittle due to some partial degradation of treated KF in cement matrix which deteriorate the fibre-matrix bonding. However, the incorporation of AASA 
into the mixtures gave significant enhancement in the residual compressive strength of KFRBCC. These test revealed after 20 wet/dry cycles $(60 \mathrm{~d})$, the compressive strength of AASA40 in NC, AC, and BC continue to dropped 43.1, 33.7, and $21 \%$ of the initial compressive strength at $56 \mathrm{~d}$. Specimens in $\mathrm{BC}$ curing show lower reduction compared to others curing conditions. Moreover, the compressive strength of KFRBCC with $40 \%$ AASA in NC, AC, and $\mathrm{BC}$ reduced by $73.8,68.3$ and $65.7 \%$ compared to their values at $180 \mathrm{~d}$ after $60 \mathrm{wet} /$ dry cycles $(180 \mathrm{~d})$.

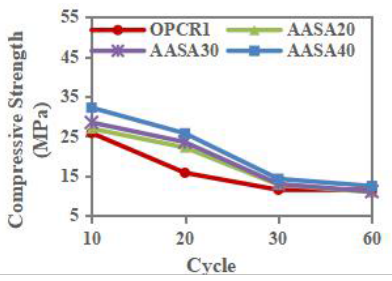

(a)

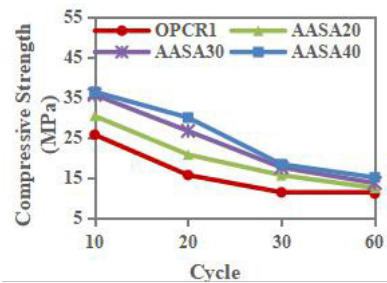

(b)

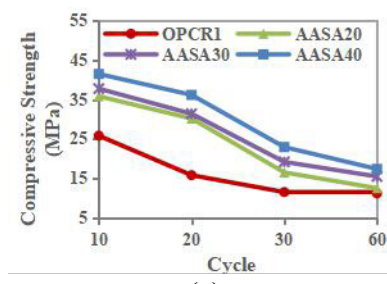

(c)

Fig. 2. Residual compressive strength prior to wet/dry cycle a) NC, b) AC and c) BC

\subsection{Microstructure analysis of the composites using BC of AASA40}

SEM investigations demonstrated different variations in the morphology of OPC and AASA mixtures with treated KF after tested with designated regimes. Small fragments of AASA40 cured in BC were taken after compressive test was used for microstructure analysis. Fig. 3 shows the SEM of all specimens after compressive strength test at designated ages. The pozzolanic reaction of AASA and filler effect have contributed to a denser microstructure and enhanced the strength particularly at $180 \mathrm{~d}$ of curing. From Fig. 3(a1-a4), all specimens shows that void and fluid structure are almost negligible. The chemical composition of the AASA used in this investigation suggests that almost negligible hydraulic activity $(0.41 \%$ of $\mathrm{CaO}$ content $)$ and a relatively high pozzolanic activity because of its $47 \%$ of $\mathrm{SiO}_{2}$ (Table 1). Therefore, the effect of using AASA on the properties of the composites will be more noticeable at later ages. Fig. 3(b1-b4) shows SEM images obtain from elevated temperatures test. There is no significant changes in the specimens when temperature increase up to $250{ }^{\circ} \mathrm{C}$. However, noticeable cracks appeared when the temperature reached $500{ }^{\circ} \mathrm{C}$, and responsible for a decrease in compressive strength. The specimens was severely damaged as a result of fibres melting but the presence of AASA contributes to the prevention of crack extension and improving the durability of cement composites.

Fig. 3(c1-c4) shows images obtain from wet/dry cycles with regards to the effect of AASA on the degradation of treated KF in a cement matrix. After 30 wet/dry ycles, the the treated KF suffer slightly degradation in the cement matrix but the fibre still manage to bridging a micro-cracks. However, with addition of AASA has helped to mitigate the degradation and resulted in high level of intactness with the embedded treated KF. Partial replacement of $40 \mathrm{wt} . \%$ AASA verified that cement modification reduce the degradation and improving the durability of treated KF. This confirms that AASA in cement modification had accelerated high pozzolanic activity and gave more significant role than its physical filling. 


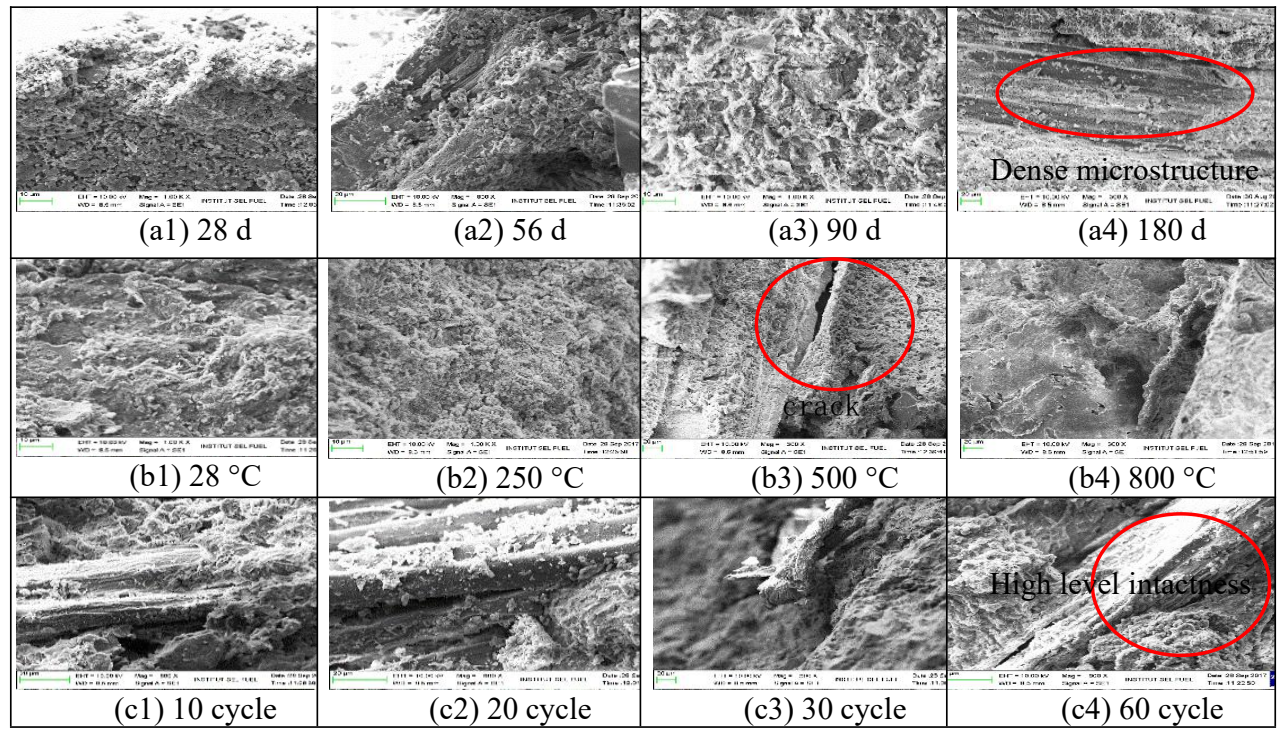

Fig. 3. SEM images of a) initial, b) elevated temperature, and c) wet/dry cycle.

\section{Conclusions}

The influences of treated KF, partially replacement of OPC with AASA, curing conditions and duration of exposure on accelerated ageing conditions on compressive strength of KBRCC are determined. The results indicate that compressive strength can increase with $\mathrm{BC}$ and longer exposure duration. Meanwhile, study on compressive strength indicates that for $\mathrm{BC}$ there were increases in strength up to $60 \%$ for $180 \mathrm{~d}$ curing period. The results also show that strength loss in KFRBCC depends on cement fineness and the regime of curing. Curing conditions has an important effect to reduce or increase the compressive strength at prolong curing periods and durability of composites after wet/dry cycle. However, the limitation of the study is rely on AASA contents which indicate that $40 \% \mathrm{wt}$. was the maximum contents for OPC replacement. The mixes will require more liquid if AASA were added beyond maximum contents and will effect the workability. In general, the strength loss was slightly lesser for AASA specimens than OPC specimens. Test results indicate that the effect of curing conditions on the durability was much lower than on the mechanical properties, and strength should not be the single control indicator while considering the effect of curing. Apart from that, the technology of internal curing and different types of pozzolans material (nanosilica, nanoclay, metakaolin, and etc.) should be taken into consideration for further research to indicate the positive impacts of aspects of KFRBCC performance.

\section{Acknowledgment}

The authors acknowledge the institution for financial supports under Fundamental Research Grant Scheme (FRGS/1/2016/TK06/UKM/02/2) and AP-2015-011.

\section{References}

1. G. Espinoza-Hijazin and M. Lopez, "Extending internal curing to concrete mixtures with W/C higher than 0.42," Constr. Build. Mater., vol. 25, no. 3, pp. 1236-1242, 2011. 
2. M. Radlinski and J. Olek, "Effects of Curing Conditions on Properties of Ternary ( Ordinary Portland Cement / Fly Ash / Silica Fume ) Concrete," no. 112, pp. 49-58, 2015.

3. A. S. Al-Gahtani, "Effect of curing methods on the properties of plain and blended cement concretes," Constr. Build. Mater., vol. 24, no. 3, pp. 308-314, 2010.

4. E. R. Grist, K. a. Paine, a. Heath, J. Norman, and H. Pinder, "Structural and durability properties of hydraulic lime-pozzolan concretes," Cem. Concr. Compos., vol. 62, pp. 212-223, 2015.

5. G. K. Al-chaar, M. Alkadi, and P. G. Asteris, "Natural Pozzolan as a Partial Substitute for Cement in Concrete," open Constr. Build. Technol. J., vol. 7, pp. 33-42, 2013.

6. S. Haruehansapong, T. Pulngern, and S. Chucheepsakul, "Effect of the particle size of nanosilica on the compressive strength and the optimum replacement content of cement mortar containing nano-SiO2," Constr. Build. Mater., vol. 50, pp. 471-477, 2014.

7. N. Y. Mostafa, Q. Mohsen, S. A. S. El-Hemaly, S. A. El-Korashy, and P. W. Brown, "High replacements of reactive pozzolan in blended cements: Microstructure and mechanical properties," Cem. Concr. Compos., vol. 32, no. 5, pp. 386-391, 2010.

8. H. M. Owaid, R. Hamid, and M. R. Taha, "Strength - Ultrasonic Pulse Velocity Relationship of Thermally Activated Alum Sludge Multiple Blended High Performance Concretes," Key Eng. Mater., vol. 594-595, pp. 521-526, 2013.

9. H. M. Owaid, R. Hamid, and M. R. R. Taha, "Influence of thermally activated alum sludge ash on the engineering properties of multiple-blended binders concretes," Constr. Build. Mater., vol. 61, pp. 216-229, Jun. 2014.

10. M. A. Tantawy, "Characterization and pozzolanic properties of calcined alum sludge," Mater. Res. Bull., vol. 61, pp. 415-421, 2015.

11. M. Frias, R. Vigil De La Villa, I. De Soto, R. Garcia, and T. A. Baloa, "Influence of activated drinking-water treatment waste on binary cement-based composite behavior: Characterization and properties," Compos. Part B Eng., vol. 60, pp. 14-20, 2014.

12. A. Yagüe, S. Valls, E. Vázquez, and F. Albareda, "Durability of concrete with addition of dry sludge from waste water treatment plants," Cem. Concr. Res., vol. 35, no. 6, pp. 1064-1073, Jun. 2005.

13. A. Benli, M. Karataş, and Y. Bakir, "An experimental study of different curing regimes on the mechanical properties and sorptivity of self-compacting mortars with fly ash and silica fume," Constr. Build. Mater., vol. 144, no. July, pp. 552-562, 2017.

14. R. Amjadi, M. Monazami, E. Mohseni, H. Azar Balgouri, and M. M. Ranjbar, "Effectiveness of different recycled materials in self-compacting mortar," Eur. J. Environ. Civ. Eng., vol. 21, no. 12, pp. 1485-1501, 2017. 